\title{
AC 2010-436: BUILDING COMMUNICATION SKILLS IN SUPPLY CHAIN MANAGEMENT AND FACILITY LOGISTICS CURRICULUM THROUGH MULTI-INSTITUTIONAL VIRTUAL TEAMING
}

\section{Suzanna Long, Missouri University of Science \& Technology}

Suzanna Long is an assistant professor of engineering management and systems engineering at Missouri S\&T. She holds a PhD and an M.S. in engineering management, B.S. in physics and a B.A. in history from the University of Missouri-Rolla (UMR) and an M.A. in history from the University of Missouri-St. Louis. Her research interests include strategic partnering in global supply chain networks, supply chain curriculum development, virtual teaming in a global marketplace, and sustainable energy management systems. She was a faculty researcher on a Business and International Education Grant funded by the Department of Education, completing projects on multimodal transport networks and international and global supply chain curriculum development. She completed preliminary work on global, multi-institutional collaborative student teams referenced in this proposal as part of the BIE grant award. Dr. Long is currently a co-investigator on a related Missouri DOT project and is an investigator on a sustainable waste water treatment project in EPA Region 7 funded by Missouri S\&T's Energy Research Development Center. Dr. Long has over twenty five conference and journal publications, is a reviewer for technical journals, holds national office in multiple technical societies, and holds membership in multiple professional societies.

\section{Hector Carlo, University of Puerto Rico}

Hector Carlo is an Assistant Professor of Industrial Engineering at The University of Puerto Rico-Mayagüez. Dr. Carlo earned a Doctor of Philosophy degree (2007) and a Master of Science in Engineering degree (2003) from the Industrial and Operations Engineering department at The University of Michigan, and a Bachelors of Science degree (2001) from the Industrial Engineering department at the University of Puerto Rico-Mayagüez. Several of his articles have appeared or are accepted to appear in scientific journals as ASME's Journal of Manufacturing Science and Engineering, Computers \& Industrial Engineering, and IIE Transactions. His research interests include Material Handling \& Logistics, and Operations Research applications to non-traditional environments such as Education, Government, Healthcare, and Tourism.

\section{Jane Fraser, Colorado State University, Pueblo}

Jane M. Fraser has been a Professor and the Chair of the Department of Engineering in the College of Education, Engineering and Professional Studies at Colorado State University-Pueblo since 1998. Dr. Fraser has a Bachelor of Arts degree in mathematics with honors from Swarthmore College, where she was elected to Phi Beta Kappa and Sigma Xi; she received her master's in 1972 and her doctorate in 1979 from University of California, Berkeley, in Industrial Engineering \& Operations Research. As a woman in engineering, Dr. Fraser has developed an understanding of what it means to be treated differently and she has applied that understanding to help others succeed. At Ohio State she conducted workshops on teaching for diversity and was the advisor for a social sorority for engineering students. She chairs CSU-Pueblo's Multicultural Council, and she is a member of the Coordinating Committee for Women's Studies at CSU-Pueblo. She is one of the organizers of Science Day, in which Pueblo area children from the Boys and Girls Clubs spend a Saturday at CSU-Pueblo in hands-on science and engineering activities. She is the CSU-Pueblo coordinator for the Colorado Alliance for Minority Participation. She was the Principal Investigator for a $\$ 485,000$ grant to CSU-Pueblo from the National Science Foundation for scholarships in Computer Science, Engineering, and Mathematics.

\section{Abhijit Gosavi, Missouri University of Science and Technology}

Abhijit Gosavi is an Assistant Professor of Engineering Management and Systems Engineering at 
Missouri S \& T. His Ph.D. is in industrial engineering with an emphasis on operations research. His research interests include supply chain management, remanufacturing, productive maintenance, and quality control. He has published in numerous journals, e.g., IIE Transactions, European Journal of Operational Research, Management Science, Automatica, and the International Journal of Production Research. In 2003, the first edition of his book entitled "Simulation-Based Optimization" was published by Kluwer Academic Publishers (now Springer). Gosavi is currently funded on an NSF grant that studies the use of machine learning algorithms for large-scale problems commonly found in manufacturing planning and airline systems. In the past, he has been funded by NSF and the Department of Defense on using simulation-based techniques for solving supply chain problems and infrastructure rebuilding. He has recently co-authored (see Shah et al., 2009) a journal paper that provides new solution techniques for sustainable manufacturing processes. He reviews papers for a number of prestigious journals in his field of research. He is a member of ASEE, IIE, POMS, and INFORMS.

\section{Scott Grasman, Missouri University of Science \& Technology}

Scott E. Grasman is an Associate Professor of Engineering Management and Systems Engineering at Missouri S\&T, having recently returned from an international visiting research position. His primary research interests relate to the application of quantitative models to manufacturing and service systems, focusing on the design and development of supply chain and logistics networks. He has been the principal investigator on projects funded by, among others, US DOT and US DOE. In addition, he has been a co-investigator on a number of related projects. Dr. Grasman is currently working on related projects funded by the US DOE (PI), US DOT (PI), Missouri DOT (PI), and the Defense Logistics Agency through the Air Force Research Lab (co-PI) as part of a larger research focus on alternative fuels. His recent work on alternative energy has resulted in much publicity in national media and numerous speaking invitations, as well as a research sabbatical in Europe. His work on sustainable development in public-private partnerships has been recognized by the United Nations Economic Commission for Europe Committee on Economic Cooperation and Integration. He is the author or co-author of over 75 technical papers, reviewer for various technical journals, on the editorial board of a new journal, and supervisor of dozens of graduate and undergraduate research students. He has also published in the area of engineering education. 


\title{
Building Communication Skills in Supply Chain Management and Facility Logistics Curriculum through Multi-institutional Virtual Teaming
}

\begin{abstract}
Engineering managers and other technology-based business professionals who possess crossorganizational and cross-cultural communication skills, along with traditional quantitative abilities, are more adept at handling the demands of the global supply chain environment. Mastery of these skills must begin in the classroom and should be an essential component of supply chain management curriculum in engineering management and industrial engineering departments. Providing real world opportunities that explore collaboration across organizational cultures, time zones, and practice gives students a tremendous competitive advantage as they enter the workforce and fosters experience-based learning. This paper details the creation of an integrated supply chain curriculum between engineering management and industrial engineering departments at four universities and examines the value-added skills achieved through the addition of a global, virtual student project environment. This partnership includes two universities in the U.S., one in Puerto Rico, and one in Spain. Assessment is addressed through both internal and external assessment mechanisms. These include the use of individual course evaluation data, pre and post-test measures of progress toward learning goals and evaluation by an external reviewer with expertise in curriculum design and course improvement.
\end{abstract}

\section{Introduction}

Global strategies and skill sets are essential to meet the challenges of the modern business environment. Engineering managers and other technology-based business professionals must be prepared to excel in a variety of social, political, and cultural settings. Awareness of these business strategies must begin in the classroom and should be an essential component of supply chain-logistics management programs. The importance of globalizing the curriculum has long been recognized as an important facet of preparing students to meet the demands of the modern marketplace. Accreditation bodies stress the importance of building programs that not only contain a global emphasis, but also include adequate assessment measures to assure student learning and success with established objectives.

This paper details an ongoing curriculum development effort between four engineering departments, two in the U.S., one in Puerto Rico, and one in Spain. The partnership between Missouri University of Science and Technology (Missouri S\&T), Colorado State UniversityPueblo (CSUP), University of Puerto Rico-Mayaguez (UPRM), and Universidad Publica de Navarra (UPNA) is developing an integrated supply chain management curriculum designed to foster effective communication skills. The collaborative environment created by the investigators allows for concurrent development of curriculum materials capable of addressing identified needs in the realm of global sustainability. The goal is to produce an educational curriculum that produces an engineer or engineering manager who has a thorough understanding of the logistics of sustainable manufacturing processes and is well able to communicate with colleagues from around the globe. The central topics will be integrated within existing course curricula in a seamless manner. A framework for using multi-institutional partnerships is developed to provide 
students with real world opportunities that explore collaboration across organizational cultures, time zones, and practice. This framework fosters experience-based learning and examines the value-added communication skills achieved through the addition of a global, virtual student project environment to supply chain-logistics management courses.

\section{Literature Review}

The globalization of the world economy and the impact of technology on workforce preparation and curriculum design are reflected in the literature and showcase a strong awareness of the value of globalizing the curriculum. This shift is readily apparent when comparing the concerns of authors in past decades over lack of global awareness with the strong advocacy and promotion of globalization in current literature $2,10,18$.

Traditional supply chain courses provide students with very limited introductions to global processes and concepts. Only $2.9 \%$ of the students sampled in the 1980 s and 90 s felt that they had sufficient knowledge of global marketing to allow them to compete in the complex international distribution system ${ }^{2,19}$. The past decade has seen improvement. This is due in part to the recognition of the importance of globalization by national accreditation bodies ${ }^{8}$. A global perspective is heavily stressed by the Accreditation Board for Engineering and Technology, Inc. (ABET), the American Assembly of Collegiate Schools of Business (AACSB) and the Association of Collegiate Business Schools and Programs (ACBSP) in their accreditation standards.

Students must possess more than technical competence. Strong communication skills are essential for global innovation and organizational effectiveness. Supply chain courses should include opportunities to practice communication skills as well as discussions of current global issues $^{18}$. Examining curriculum design for many engineering management and management of technology programs reveals a lack of conceptual focus on key business issues. The bulk stress mathematical decision theory as a first priority followed by management process. This does a disservice to students by providing inadequate emphasis on interpersonal communications and leadership. These issues are equally critical for effective curriculum design in areas such as transportation-logistics ${ }^{7}$.

The existing literature shares common threads stressing the necessity of preparing today's students for a world shaped by global processes and communication patterns. An important first step is awareness that what works for one country may not guarantee success in another. Reducing ethnocentricity in students can be accomplished by the addition of coursework exploring the global perspective or redesigning existing curriculum to include global components. A redesign that infuses global concepts throughout a student's degree program may prove effective in providing skills and experiences that will provide students with a greater awareness of the impact of globalization on the modern workforce. The remainder of this paper showcases a multi-institutional collaborative designed to create a framework for structured, global projects across international borders and university boundaries. 


\section{Collaborative Partnering Framework: Development of Integrated Coursework}

A global, multi-institutional partnership between four engineering departments is used to address a recognized need to create true opportunities for global learning ${ }^{15,16}$ by future engineering managers. Globalization of students and programs must be infused through a united front from university governing bodies to the classroom ${ }^{10}$. Cross-cultural training programs that devise methodologies to assist students in the development of goals and take into consideration the role those goals play on student development of skills is the most effective in providing global frameworks ${ }^{11}$. Integration will be accomplished on several levels. Common themes of global sustainability and scalability are introduced in existing courses. Teaching cases, notes, and other materials are being developed for use in all partner institutions by faculty collaborators. Faculty will develop learning goals, objectives, and assessments for themed materials using virtual collaborative software. Integration is reinforced through the creation of multi-institution student group projects on themed materials. Faculty exchanges and virtual interaction with student groups from all institutions will simulate organizational complexity for participating students and provide diverse points of view and experiences that will further enhance learning opportunities. Group projects will cross institutional and course boundaries to develop knowledge of crossfunctional teams beyond textbook descriptions. Student participants are at the senior/graduate level; each team will include students from all partner schools and relevant course offerings during any given semester (see Table 1).

Courses are being redesigned to add vital components necessary to implement this pedagogy. A table of equivalent courses for partner schools is presented below. Course descriptions, syllabi, curriculum modules, and other materials will be available as completed through a project website. This table identifies relevant topics needed for the integrated curriculum and coordinates the topic with existing courses offered at all partner universities. In some cases topics are covered in multiple courses or combined. This is indicated as appropriate in Table 1.

\begin{tabular}{|l|l|l|l|l|}
\hline Course Topic & $\begin{array}{l}\text { Missouri } \\
\text { S\&T }\end{array}$ & CSUP & UPRM & UPNA \\
\hline Supply chain management & EMGT 366 & EN 477 & ININ 4075 & 88322 \\
\hline $\begin{array}{l}\text { Industrial Systems } \\
\text { Simulations }\end{array}$ & EMGT 356 & EN 420 & $\begin{array}{l}\text { ININ 4022 / } \\
\text { ININ 4018 }\end{array}$ & 35419 \\
\hline $\begin{array}{l}\text { Production Planning and } \\
\text { Scheduling }\end{array}$ & EMGT 372 & EN 477 & ININ 4039 & 35422 \\
\hline $\begin{array}{l}\text { Materials Handling and } \\
\text { Plant Layout }\end{array}$ & EMGT 257 & EN 475 & ININ 4040 & Various \\
\hline Facilities Planning & EMGT 357 & EN 475 & ININ 4040 & 35422 \\
\hline
\end{tabular}

Table 1: Courses by Topic for All Partners

\section{Global Collaborative Learning: Use of Virtual Teams}

The collaborative projects approach was designed as the equivalent of a multi-institutional capstone course. Research teams consist of students from all cooperating institutions. Students 
are required to collaborate on course projects utilizing various methods of communication and contact consistent with the creation of an international classroom ${ }^{12}$. This approach provides the basis for an experience with global, sustainable supply chain issues, and also provides students with experience in a real world of intercultural communications, time zones, time management and virtual teaming. Although project descriptions are provided, deliberate ambiguity is created in terms of the establishment of milestones and project objectives to more naturally simulate virtual teaming in global organizations.

Pedagogy is developed for global supply chain and materials/infrastructure education programs that incorporate global virtual teams as part of a methodology for producing global knowledge workers. Virtual teams are defined as groups of geographically and organizationally dispersed knowledge workers brought together across time and space through information and communication technologies (i.e., email, videoconferencing, or other computer-mediated communication system) on an "as-needed basis" in response to specific needs or to complete unique projects $^{13,14,9,3}$. Members of these working arrangements rarely, if ever, see each other.

To be considered virtual, a team must have three attributes. First, it must be a functioning team, a collection of individuals who are interdependent in their tasks, share responsibility for outcomes, see themselves and are viewed by others as an intact social unit embedded in one of more social systems, and collectively manage their relationships across organizational boundaries $^{4,6,1}$. This requirement differentiates this working arrangement from groups. Simply communicating with others electronically does not transform a grouping of people into a virtual team. Virtual teams must have real tasks to perform, interdependent members, and shared outcomes which are of higher quality than outcomes obtained if members had worked separately and all individual efforts were combined. Awareness of these factors will be incorporated into project guidelines and teaching notes. Finally, the challenges of virtual team leadership will be addressed through identification of leadership roles. The standard virtual team consists of two types of leaders: the task leader, and the social leader ${ }^{14}$. The task leader is oriented to the activities of the team, and makes decisions required to accomplish results. In a similar vein to earlier theories regarding task-oriented leadership (e.g., the Managerial Grid), meeting productivity measures is the determinant of success for this leader. The social leader is oriented toward creating feelings of group identity, status, attractiveness, and personal satisfaction. A cohesive team is the determinant of success for this leader, and is equally critical to the virtual team for maintenance.

Students are assigned to teams consisting of students from all partner universities and required to collaborate on course projects utilizing various methods of communication and contact consistent with the creation of an international classroom ${ }^{12}$. This approach provides the basis for an experience with global supply chain issues, and also provides students with real-world experience in intercultural communications, time zones, time management and virtual teaming. Projects are comparative in nature between organizational supply chain management approaches across international boundaries. This allows each team to have familiarity with supply chain elements common in their own region, but also requires that each team member study and learn from team members about another culture. Example projects include electric vehicles manufacture and hydrogen fuel cell powered industrial forklifts. 
Team project presentations are required and must include input from all virtual teammates. This further emphasizes the demands of asynchronous work in a global workforce. The structure of the class projects will include goal setting behavior for the projects and intercultural relations. Research has shown that goal setting behavior significantly enhances the participant's performance ${ }^{17}$ and plays an instrumental role in improving the student's self-efficacy and intrinsic interest in the task. In addition the course design allows for the creation of specific tasks, roles, and learning goals. Specifically, each student is assigned tasks and is part of a teamdirected management structure; this structure includes the election of leaders for each sub-team and the team at large. In addition, tasks are divided up into smaller focused tasks with frequent reporting requirements, and specific questions that explore intercultural relations, communications and learning styles must be included. This specific task, role and learning goal focus has been identified as the necessary components for a successful intercultural learning environment ${ }^{5}$. The structure of the class projects was specifically designed to include goal setting behavior for the projects and intercultural relations. Research has shown that goal setting behavior significantly enhances a participant's performance ${ }^{17}$ and plays an instrumental role in improving student self-efficacy and intrinsic interest in the task. In addition the course design allows for the creation of specific tasks, roles, and learning goals. Specifically, each student is identified as either project manager or researcher; tasks are divided up into smaller focused tasks with frequent reporting requirements, and specific questions directed toward the intercultural relations, communications and learning are included. This specific task, role and learning goal focus has been identified as a necessary component for a successful intercultural learning environment ${ }^{5}$.

\section{Assessment}

Assessment of project results are evaluated using an external reviewer through a combination of pre- and post-test assessments of student learning in the realm of sustainability, measures of global knowledge and multicultural learning, and student engagement. The assessment framework is used to evaluate the ongoing project activities and the overall performance. It consists of two types of evaluation: Implementation Evaluation and Performance Evaluation. Implementation Evaluation is performed to assess whether the project is being conducted as planned. Performance Evaluation assesses the progress made by the participants in meeting the project goals, and evaluates the extent to which the outcomes have been realized.

In order to document outcomes of the project, participating students complete pre and post online surveys adapted from prior successful programs. Survey questions pertain to the direct benefits of the program (e.g., attitudes toward sustainability, acquisition of a range of skills, interest in a career in science or engineering, self-confidence, and student perceptions of experiences with virtual teaming). To assess whether course experiences lead to change in participants' dispositions or beliefs, the program will use pre and post online surveys designed to gather information on students' attitudes, skills, self-confidence, interest in careers, and perceptions of experiences related to integrated virtual teaming. For virtual teaming metrics include communication level, leadership, and performance as a unit ${ }^{4,6,1}$. Quantitative data will be analyzed with the Statistical Package for the Social Sciences (SPSS) to test for statistically significant differences from pre to post. 
Faculty mentors also complete online surveys. Since mentoring is one of the hardest, yet most rewarding activities in the program, survey questions clarify outcomes of mentoring relationships and probe for descriptive information specific to the experience. It is important to document direct benefits of the program in terms of continued participation in activities, retention in engineering and science majors, academic performance in related courses, changes in selfconfidence, and pursuit of career goals. Thus, the program will maintain a database of participants, including demographic information, major, research work, and career.

\section{Directions for Future Research and Preliminary Conclusions}

Although concepts of globalization and effective communication are being integrated into the curriculum, the effectiveness of methods has not yet been fully analyzed. The full implications of what this means in terms of longitudinal success beyond the classroom experience has yet to be determined. What does it mean to fully integrate a curriculum? Attitudes may change over the course of a semester, but are these changes long-term? Do changes in attitude continue into the workplace after graduation? Future research will examine these questions and the extent to which attitudes are changed and a more global perspective is achieved by tracking graduates of the program into the workforce and conducting periodic surveys to determine whether enthusiasm and perceived value for the instructional approach has waned over time.

A function of education is to broaden the global understanding of those under our charge. Just as we equip students with the technical competencies necessary to function as local business professionals, we must also prepare students with a global perspective that can allow them to function wherever opportunities lie. Today's marketplace and virtual business environs showcase this on a daily basis. To fail to recognize this or to keep diversity limited to the context of the workplace does a great disservice to our students. We are an increasingly global community. Increasing numbers of US-based companies are seeking markets in foreign countries, and as well as corresponding increases in international companies doing business in the United States. Not everyone with whom we interact on a daily basis will share our values or customs regarding work. Seeking to understand the business models and cultures that impact the supply chain of regional business provides skills that enhance the chances for success for future engineers and engineering managers both in the classroom and the workplace.

\section{Acknowledgements}

The authors wish to thank the NSF for their generous support of this project. We also thank Dr. Leonardo Bedoyavalencia, Colorado State University-Pueblo, Assistant Professor and instructor of one of the CSU-Pueblo courses, who joined the team in Spring 2010 and Laura Collins, Center for Research and Learning, external assessment specialist for the project.

\section{References}

1. Alderfer, Clayton P., (1977) Group and intergroup relations, In: Improving Life at Work, Hackman, J. Richard and J. Lloyd Suttle, (eds.), Santa Monica, CA: Goodyear. 
2. Bess, H. David and Collison, Frederick. (1987). Transportation and Logistics Curricula: Still Too Domestic? Transportation Journal, 26 (3), 48-58.

3. DeSanctis, Gerardine and Poole, Marshall S., (1997) Transitions in teamwork in new organizational forms, Advances in Group Processes, Vol. 14, pp. 157-176.

4. Forsyth, Donelson R., (1999) Group Dynamics, New York: Wadsworth Publishing Company.

5. Gabb, D., (2006) Transcultural Dynamics in the Classroom. Journal of Studies in International Education. 10(4) 357-368.

6. Hackman, J. Richard, (1987) The design of work teams, In: Handbook of Organizational Behavior, Jay W. Lorsch, (ed.), Englewood Cliffs, NJ: Prentice-Hall, 1987.

7. Hicks, Philip C., Westbrook, Jerry D., and Utley, Dawn R. (1999). What are We Teaching Our Engineering Managers? Engineering Management Journal, 11(1), 29-34.

8. Hoffman, William. (2005, January 10). Logistics’ Evolving Curriculum. Traffic World, 19-21.

9. Jarvenpaa, Sirkka L, and Leidner, Dorothy E., (1998) Communication and trust in global virtual teams, Journal of Computer Mediated Communication, Vol. 3, No. 4.

10. Jefferson, R. W., (2001) Preparing for Globalization-Do We Need Structural Change for Our Academic Programs? Journal of Education for Business, 76(3), 160-166.

11. Kitsantas, A., (2004) Studying Abroad: The Role of College Students' Goals on the Development of CrossCultural Skills and Global Understanding. College Student Journal, 38(3), 441 -452.

12. Leask, B., (2004) Internationalisation Outcomes for All Students Using Information and Communication Technologies (ICTs). Journal of Studies in International Education. 8(4) 336-351.

13. Lipnack, Jessica and Stamps, Jeffrey, (2000) Virtual Teams: People Working Across Boundaries with Technology, $2^{\text {nd. }}$ Edition, New York: John Wiley \& Sons, Inc.

14. Lipnack, Jessica and Stamps, Jeffrey, (1997) Virtual Teams: Reaching Across Space, Time, and Organizations with Technology, New York: John Wiley and Sons.

15. Lohman, J., (2008) A Rising Global Discipline, Journal of Engineering Education 97 (3) 227-230.

16. Sheppard, S., Pellegrino, J. and Olds., B., (2008) On Becoming a 21st Century Engineer, Journal of Engineering Education 97 (3) 231-235.

17. Shunk, D. H. (2000). Learning theories: An educational Perspective (3rd edition). Prentice Hall.

18. Tryggvason, Gretar and Apelian, Diran. (2006). Re-Engineering Engineering Education for the Challenges of the 21 st Century. Journal of Management, 58 (10), 14-17.

19. Turley, L.W. and Shannon, J. Richard. (1999). The International Marketing Curriculum: Views from Students. Journal of Marketing Education, 21 (3), 175-181. 